\title{
Design and Realization of Temperature Measurement System based on PROTEUS Software
}

\author{
C.L. Wang, P.Y. Chen, H.L. Hu \\ The School of Physics and Electronic Engineering \\ Xingtai University \\ Xingtai, 054001, China
}

\begin{abstract}
Computer aided design is an important method in industrial design. The process of single chip micro-controller unit (MCU) based on Proteus simulation software is ocular, rapid, easy debugging, with low cost and high efficiency. DS18B20 temperature sensor has high accuracy, wide range and anti-interference properties. Hardware design, software editing, component welding and system debugging are involved in circuit design. Under the environment of Proteus, the hardware design and software debugging of single chip micro-controller and digital circuit can be completed easily. This can shorten the cycle of product development and enhance design efficiency. It can be applied to the $t$ range of temperature occasions from $-55^{\circ} \mathrm{C}$ to $+125^{\circ} \mathrm{C}$.
\end{abstract}

Keywords-temperature; proteus software; simulation; microcontroller; design

\section{INTRODUCTION}

With the development of computer technology, all kinds of computer-aided design and production increase daily. Man-machine dialogue is a kind of work mode which is used in industrial design. The computer has interactive, rapid access and automatic processing and other functions. It can not only show the design effect and high efficiency, but also can do further simulation of the design content, show even 3D virtual component, device or product. The production of temperature measurement system is based on Proteus simulation software, combined with the microcontroller circuit principle. The circuit design process involves the hardware design, software programming, component and system for welding debugging. The design of hardware and software, the single-chip microcomputer and digital electronic circuit and convenient debugging can be completed in the Proteus environment. The product development cycle can be shortened and the design efficiency improved.

The purpose of this paper is to demonstrate the temperature measurement system which is designed under the Proteus software. First it shows the circuit, then programming, finally simulates the virtual system.

\section{CIRCUIT OF PRINCIPLE}

Temperature measurement system is mainly composed of single chip AT89C51 control chip, DS18B20 temperature sensor, liquid crystal monitor LCD1602 components.

AT89C51 is a kind of lower voltage, high performance CMOS 8 bit micro-processor with $4 \mathrm{kbit}$ flash
register(FPEROM-Flash Programmable and Erasable Read Only Memory).

DS18B20 Is a Tiny Temperature Sensor. Its range is $-55^{\circ} \mathrm{C} \sim+125^{\circ} \mathrm{C}$. In the range of $-10 \sim+85^{\circ} \mathrm{C}$, the accuracy is $\pm 0.5^{\circ} \mathrm{C}$. The field temperature is transmitted directly by way of "first bus line" digit mode, thus the anti-interference of the system is greatly enhanced. This tiny temperature sensor is suitable for the measurement of field temperature in abominable environment. DS18B20 only need to be connected with micro-processor by way of one port line to achieve bi-directional communication. It communicates with the MCU of AT89C51 through single bus protocol. The AT89C51 port of P3.3 connects the DQ end of DS18B20 chip. LCD1602 links the SCM P0. P2 port of AT89C51 .The main function of MCU AT89C51 is to control and complete the collection of temperature and display information. The schematic diagram drawn by the Proteus software interface is shown in figure $1[1$, 2].

Liquid crystal 1602LCD refers to liquid crystal module (displays characters and numbers) which displays the content of 16X2, i.e. display two lines and each line has 16 characters. Most character liquid crystal is based on 16X2 liquid crystal chip [3]. Liquid crystal LCD1602 monitor is connected with the $\mathrm{P} 0$ and $\mathrm{P} 2$ ports of single chip micro-controller. The single chip micro-controller controls and completes the temperature collection and information display.

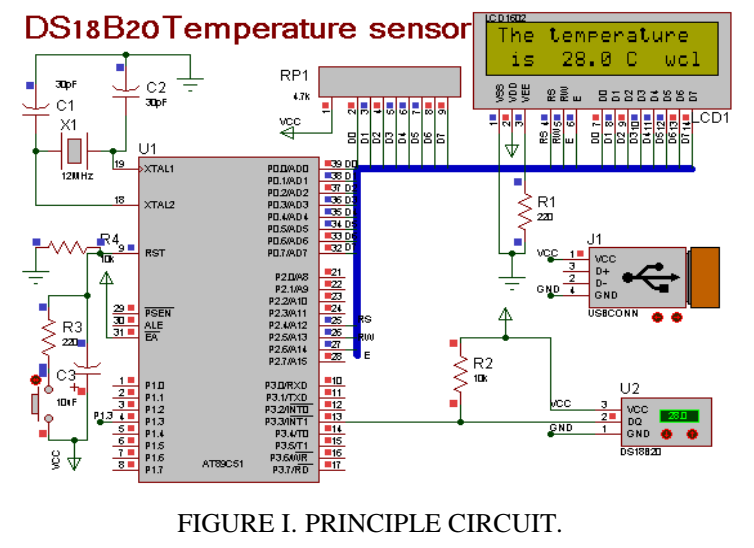

\section{Source Program Design}

The editing of source program mainly includes the realization of temperature acquisition, its display and control module. They are the temperature sensor DS18B20 reading and 
writing program, the display program of LCD1602 and microcontroller control program. DS18B20 temperature reading programming is given as below $[4,5]$ :

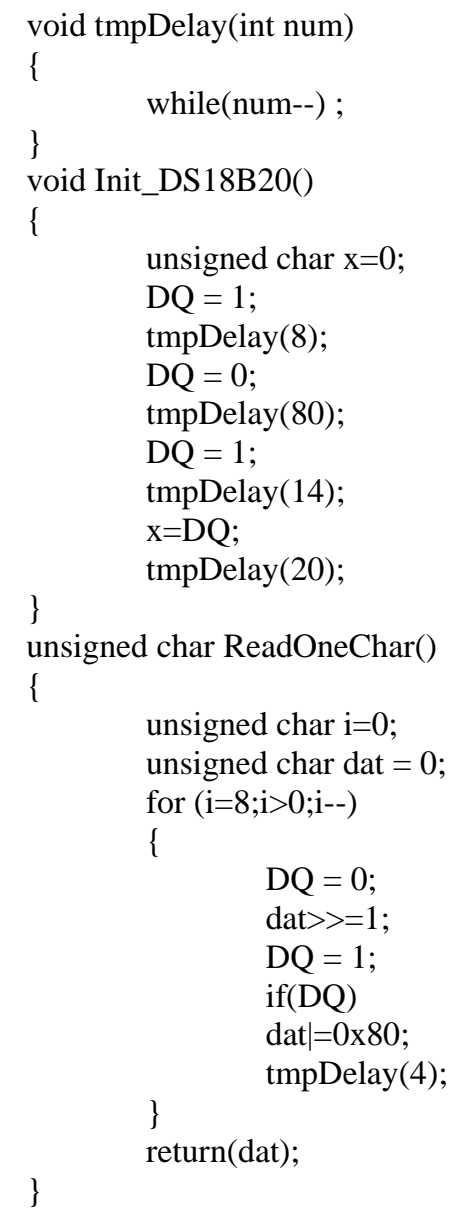

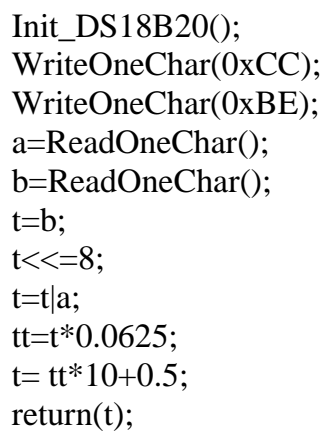

The program can be written or compiled directly in the Proteus software platform. Then copy the generated HEX files into AT89C51. One can also open the Keil and uVision3 software[1,6,7,8,9]. Click the new project in the menu. After pop-up the dialog box, create a project file and select the SCM model. Write the original program. When the program is completed, click the compile connection and compile, which generates hex files. Check and see no error appears, create target (18B20.hex) file.

\section{CiRCUit Simulation}

The circuit debugging and analysis can be done under the Proteus software. Operate the loaded single chip controller target file and the simulation result will be given.

Open the already drawn schematic of design circuit on the platform of Proteus software and double click on the AT89C51 microcontroller. Show the edit element window, generates the source object code (18B20.hex) file and upload it into the microcontroller. This file is compiled as sixteen hexadecimal HEX file and it is shown as in figure 2. Then select suitable simulation method to analyze and debug design circuit. Third, Click "run" button to begin the simulation. System simulation result is shown in figure 1 . Fourth, change the parameters and watch simulation results, then analyze the influence of parameters on the performance of the circuit [7, 8]. Fifth, Check the CPU registers, memory data changes. Figure 3, figure 4, Figure 5 show the CPU SFR Memory, CPU Registers and CPU Internal Memory data changes when the program are running respectively.

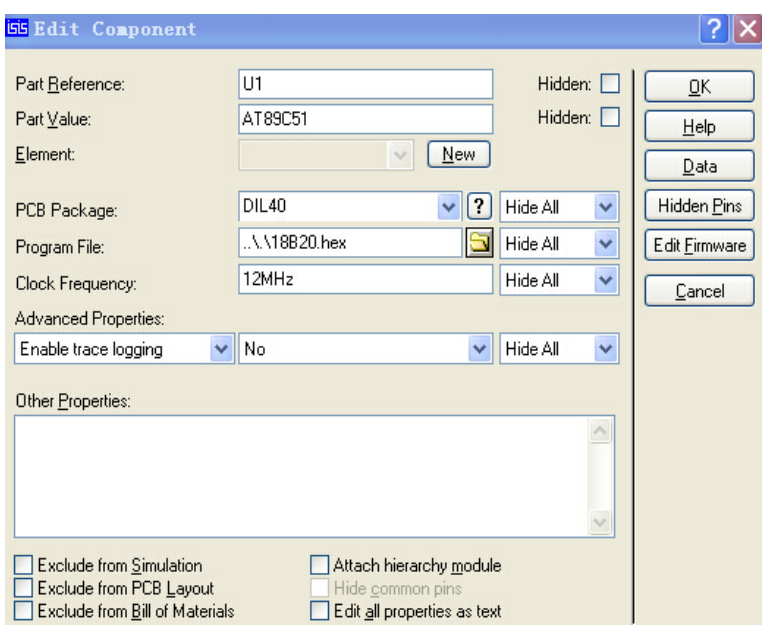

FIGURE II. EDIT WINDOW OF PARTS. 


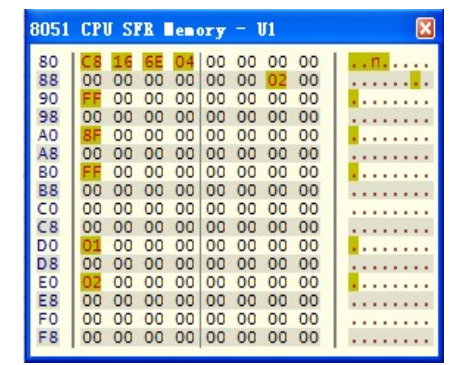

FIGURE III. 8051 CPU SFR MEMORY

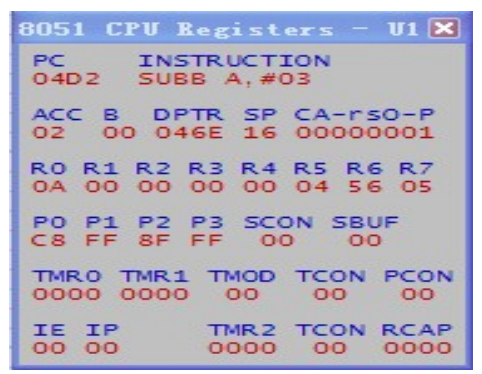

FIGURE IV. 8051 CPU REGISTERS.

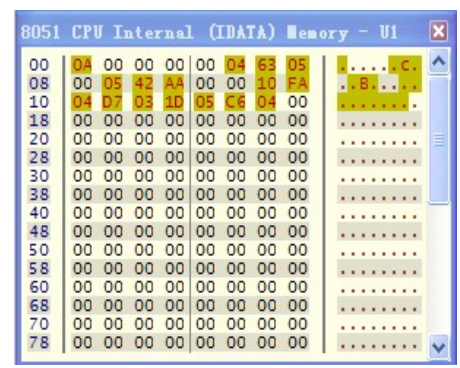

FIGURE V. INTERNAL MEMORY.

\section{PCB CIRCUIT BOARD DESIGN}

(1) Click the 'toolbox' of 'ARES' interface. Search 'component placement and editing' icon, select the elements in the list and click the left mouse button in a frame, put the selected element. (2) After placed element, click 'Tools'- 'Auto Router' from the menu. Dialog box, click the 'Begin Routing' button in the presence dialog box, it can be automatically complete the wiring. (3) Set level,set the rules, inspect wiring, check cyclic redundancy, check the design planning. (4) Click 'output' on the menu bar, and then click 'Gerber and Excellon output', open the dialog box, start to design. Generate Gerber file. Click 'output' on the menu bar again, then click 'Gerber view', pop up 'Gerber view', and check the selected optical drawing layer. Finish the final circuit PCB board. (5)When the wiring is completed, the $3 \mathrm{D}$ simulation effect is shown as figure 6.

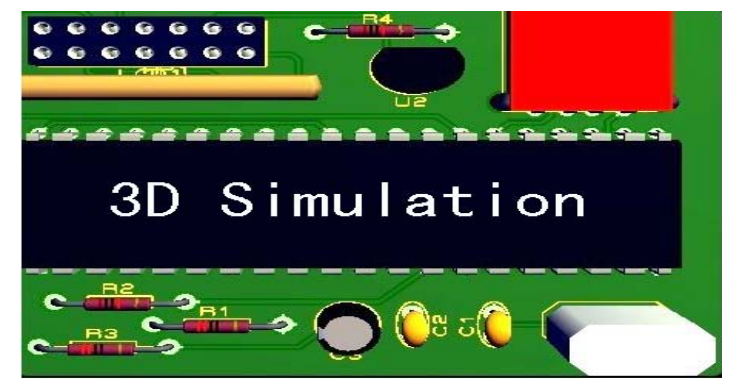

FIGURE VI. 3D SIMULATION.

\section{SUMMARY}

Proteus circuit simulation fully reflects the ideas of circuit design, software design, circuit simulation, PCB circuit board design, the circuit welding and system debugging. The full understanding of the principle of the circuit is achieved from qualitative analysis to quantitative analysis; the achievement is realized from pure theory to the analysis of circuit design, circuit simulation experiment; the realization is achieved of the PCB circuit board design to the actual hardware installation and debugging. The simulation analysis and fabrication become the bridge from pure theory to practice. The design process is intuitive and quick to the comprehensive development of new products effectively. According to different applications, one can put the module package in other equipments, such as the realization of cable trench, water circulation system, air conditioning temperature control, agricultural greenhouse environment control temperature occasions.

\section{ACKNOWLEDGMENT}

This Project has been supported by Xingtai University.

\section{REFERENCES}

[1] He Jingkai. SCM System Design, Simulation and Application -- Based on the Keil and Proteus Simulation Platform [M]. Xi'an: Xi'an Electronic Science and Technology University Press, 2011.2 (in Chinese)

[2] Li Quanli. The SCM Theory and Interface Technology [M]. Beijing: Higher Education Press, 2013.12

[3] Yu chengbo. Sensor and Automatic Detection Technology [M]. Beijing: Higher Education Press, 2009.7 (in Chinese)

[4] Ding Xiangrong. C language Program Design and Keil C [M]. Guangdong: Guangdong Higher Education Press, 2013.9 (in Chinese)

[5] Geng Zhaoying.C, Application Programming Tutorial [M]. Beijing: People's Posts and Telecommunications Press, 2010.11 (in Chinese)

[6] Xu Aijun. Keil C51 Microcontroller High-level Language Application Programming and Practice [M]. Beijing: Publishing House of electronics industry, 2013.12

[7] Zhang Yigang. Principle and Application of Single Chip Microcomputer --C51 Programming +Proteus Simulation [M]. Beijing: Higher Education Press, 2012.11 (in Chinese)

[8] Du Shuqing. Based on Proteus and Keil C51 Microcontroller Design and Simulation [M]. Beijing: Publishing House of Electronics Industry, 2012.2

[9] Zhu Qinghui.Proteus Tutorial - electronic Circuit Design, Plate Making and Simulation [M]. Beijing: Tsinghua University Press, 2011.6 